\title{
Association between Parkinson's disease and diabetes: data from NEDICES
}

\section{study}

Eduardo De Pablo-Fernandez¹, MD; Fernando Sierra-Hidalgo ${ }^{2,3}, \mathrm{MD}$, PhD; Julián Benito-León ${ }^{3,4,5}, \mathrm{MD}$, PhD; Félix Bermejo-Pareja ${ }^{3,4,5}$ MD, PhD.

1. Reta Lila Weston Institute of Neurological Studies, UCL Institute of Neurology, London, UK.

2. Neurology Department, Infanta Leonor University Hospital, Madrid, Spain.

3. Department of Neurology, University Hospital "12 de Octubre", Madrid, Spain.

4. Center of Biomedical Network Research on neurodegenerative diseases (CIBERNED), Madrid, Spain.

5. Department of Medicine, Complutense University, Madrid, Spain.

Corresponding author: E De Pablo-Fernandez; Reta Lila Weston Institute of Neurological Studies, UCL Institute of Neurology, 1 Wakefield Street, WC1N 1PJ London, UK. Tel: +44 (0)20 7679 4025; fax: +44 (0)20 7278 4993. E-mail: eduardo.fernandez.13@ucl.ac.uk 
Running title: Parkinson's disease and diabetes

Keywords: cross-sectional study; diabetes mellitus; neuroepidemiology;

neurodegeneration; Parkinson's disease.

Manuscript word count: 1487 


\section{ABSTRACT}

Background: Despite growing evidence showing an association between Parkinson's disease (PD) and diabetes, epidemiological studies have shown conflicting results.

Aims of the study: To evaluate the association between PD and diabetes, and the impact of diabetes duration in this association in an elderly ( $\geq 65$ years) Spanish population.

Methods: Data for this cross-sectional population-based analysis were obtained from NEDICES study. Subjects were identified from census list. Diagnosis of PD was confirmed by neurological examination. Diabetes was defined by self-report, being on anti-diabetic medication or diagnosis on medical records. Logistic regression analysis adjusted by potential confounders was performed to estimate the association between both conditions and also after dividing patients into short-duration $(<10$ years) and long-duration ( $\geq 10$ years) diabetes.

Results: 4998 subjects were included (79 PD and 4919 controls). Univariate analysis did not show any association between prevalence of PD and diabetes (OR 1.89, 95\% $\mathrm{Cl} 0.90-3.98, P=0.09$ ) though subgroup analysis showed a positive association in those with long-duration diabetes $(3.27,95 \% \mathrm{Cl} 1.21-8.85, P=0.02)$.

Conclusions: diabetes duration might be an important factor in the association between PD and diabetes and the risk might be limited to those with longer disease duration. 


\section{Introduction}

Increasing evidence suggests that insulin dysregulation and diabetes might contribute to the development of Parkinson's disease (PD) by shared molecular pathways. ${ }^{1-3}$ However, this potential association remains controversial from an epidemiological perspective. The aim of the present study is to evaluate the relationship between PD and diabetes in the baseline assessment of the Neurological Disorders in Central Spain (NEDICES) study and evaluate the potential role of diabetes duration in that association.

\section{Methods}

\section{Study population}

NEDICES study is a longitudinal population-based survey carried out between 19942007 assessing community-dwelling $\geq 65$ year-old individuals in order to estimate prevalence, incidence and determinants of major age-associated neurological conditions. ${ }^{4}$ Study protocol was approved by the local ethics institution and all subjects signed an informed consent at enrolment. Detailed of the study population and sampling methods have been published elsewhere. ${ }^{4-6}$ Briefly, subjects were selected by means of census lists from three different populations in central Spain in 1994-1995. Data from this baseline cross-sectional evaluation were used for this study.

Diagnosis of Parkinson's disease and diabetes 
All those subjects who screened positive on the initial validated screening questionnaire for parkinsonism were assessed and examined by a senior neurologist to confirm the diagnosis of PD. ${ }^{5,6}$ PD was defined by the presence of 2 cardinal signs of bradykinesia, resting tremor, rigidity and impairment of postural reflexes (or 1 cardinal sign in those on antiparkinsonian medication) and exclusion of other causes of parkinsonism. Only subjects with idiopathic PD were included in the study (Table 1).

Diabetes was defined by self-reported diagnosis, treatment with antidiabetic medication (oral antidiabetics and/or insulin), or diagnosis present on medical records. Subjects lacking data on diabetes status were excluded from the analysis.

\section{Statistical analysis}

Variables were not normally distributed (for each Shapiro-Wilk test, $P<0.001$ ). Chisquared or Fisher's exact tests were used for categorical variables and Wilcoxon test for continuous or ordinal variables. All the tests were two-sided and a value of $P<0.05$ was considered statistically significant. Statistical analyses were performed using the statistical software Stata 12 (StataCorp, TX).

Adjusted binary logistic regression analyses were performed with PD as the dependent variable and diabetes (presence/absence) as the independent variable. To assess the association between PD and diabetes duration patients were divided into short-duration ( $<10$ years) and long-duration diabetes ( $\geq 10$ years) as per previous studies in the literature. 7,8 Potential confounding was controlled by including demographics (gender, age); cardiovascular risk factors, previous cerebrovascular disease and antidiabetic treatment. 


\section{Results}

This study included 4,998 subjects from a total of 6,395 community-dwelling elders

(Fig. 1). Their baseline demographic and medical characteristics are shown in Table

2. There were 2,121 men and 2,877 women with a median age of 73 years

(interquartile range -IQR 68 - 79). The diagnosis of prevalent PD was confirmed in 79 subjects (1.6\%). Diabetes was diagnosed in 842 subjects (16.8\%) with a median duration of 5 years (IQR 2-13), though the information on disease duration was only available in 657 subjects. Main variables did not differ between both groups although PD subjects were slightly older $(P<0.001)$ and with a higher frequency of male gender $(P=0.03)$ than controls (Table 2$)$.

Prevalence of diabetes did not show any significant differences among PD (17.7\%) and non-PD patients (16.8\%) and the crude (unadjusted) prevalence ratio for PD among diabetics vs non-diabetics was $1.06(95 \% \mathrm{Cl} 0.60-1.89, P=0.83)$. Results of the adjusted analysis did not modify the results of this association (OR 1.89, 95\% $\mathrm{Cl} 0.90-3.98, P=0.09$ ). Covariates significantly associated to prevalent $\mathrm{PD}$ in this model were age (OR 1.05 per year, $95 \% \mathrm{Cl} 1.01-1.09, P=0.014)$, and male gender (OR 4.06, 95\% Cl $2.03-8.12, P<0.001$ ) whilst current smoking showed a negative association to PD (OR $0.23,95 \% \mathrm{Cl} 0.06-0.83, P=0.024)$.

Participants were divided according to diabetes duration. All patients with PD were included in this analysis but only 643 out of 828 diabetic controls $(77.7 \%)$ had this information available. Groups did not differ in age or gender. Results showed a significant positive association between the longer diabetes duration group with prevalent PD after adjustment for potential confounders (reference: no diabetes; OR 
for short-duration diabetes $1.68,95 \% \mathrm{Cl} 0.70-4.03, P=0.24 ;$ OR for long-duration diabetes $3.27,95 \% \mathrm{Cl} 1.21-8.85, P=0.02)$.

A summary of the results of the statistical analysis with the associations between different groups is shown in Table 3.

\section{Discussion}

In this large population-based cross-sectional study we found no significant association between diabetes and PD among Spanish elderly. However our results suggest that diabetes duration might be an important factor on this association and the risk of PD might be limited to those patients with long-duration diabetes as there was a significant positive association between PD and those patients with longduration diabetes (>10years duration).

Our study did not show a significant association between PD and diabetes in our sample population ( $\mathrm{OR} 1.89,95 \% \mathrm{Cl} 0.90-3.98, P=0.09)$. Results of observational studies evaluating this association are conflicting ${ }^{9,10}$ although in recent metaanalysis of prospective studies diabetes was found to be a risk factor for future PD $(\mathrm{RR}=1.26[95 \% \mathrm{Cl} 1.03-1.55] ; \mathrm{p}<0.0001) .{ }^{11,12}$

To our knowledge, the potential time-dependent effect of the association has been assessed only in two previous studies. ${ }^{7,8}$ Our results are in agreement with those of the Xu et $a l^{8}$ showing that most of the risk is attributed to patients with disease duration of more than 10 years. The effect of diabetes duration is important in the interest of giving a pathophysiological explanation of the association, as if diabetes is a risk factor for PD, one will expect a higher risk among those with long history or 
complicated diabetes. Driver et $a l^{7}$ found that the increased risk for PD was highest among individuals with uncomplicated or short-duration diabetes ( $<10$ years of duration) which was explained by the authors as a possible selection bias from increased medical surveillance or an underlying common biological mechanism.

The heterogeneity of the published studies, ascertainment of PD and diabetes, and the effect that environment, ethnic factors and diabetes medications might have on the association, might explain in part the inconsistency of the results. Unfortunately detailed information on diabetes control and medications were not available in our cohort and the influence that this may have on the risk of PD could not be assessed.

One of the main strengths of our study is the confirmation of PD diagnosis by a neurologist in all cases. PD cases in our study were identified from the census list in three different communities irrespective of their medical care with a more representative sample of the population with a low chance of selection bias among community-dwelling subjects. Results were adjusted by multiple potential confounders using defined and validated information obtained through face-to-face interviews including vascular risk factors and cases of vascular parkinsonism were excluded. On the other hand, our study included a relatively small number of PD patients $(n=79)$ and therefore results should be interpreted with caution before making any firm conclusions. The cross-sectional design of the study and the lack of information about the temporal relation between the two diagnoses do not allow establishing the direction of the causal relationship between diabetes and PD.

Apart from the observational studies discussed above, there is growing evidence from various areas of research suggesting a common link between diabetes and PD. It has been hypothesised that aberrant insulin signalling triggers a step wise 
sequence of disruptions of regulatory pathways (including mitochondrial dysfunction, neuroinflammation, increased endoplasmic reticulum stress, abnormal protein aggregation and metabolic abnormalities) which would lead to insulin resistance and diabetes, and might ultimately put an individual at increased risk for PD. ${ }^{1-3}$ In addition to a potential increased risk for PD, diabetes has also been suggested as a modifying factor of the disease contributing to more severe motor symptoms requiring higher doses of levodopa for symptom control, ${ }^{13}$ more prominent axial motor symptoms and cognitive impairment. ${ }^{14}$ The possibility that PD and diabetes share dysregulated pathways is particularly important as further study of these mechanisms might lead to more effective treatments or disease modifying therapies for PD and diabetes. In this regard, exenatide, a synthetic agonist for the glucagon-like peptide 1 receptor recently granted for the treatment of diabetes, has been shown neuroprotective effect in an initial open label randomised controlled trial comparing 20 patients with PD treated with exenatide and 24 PD patients acting as controls. ${ }^{15}$

\section{Conclusions}

The results of this population-based cross-sectional study shows no significant association between PD and diabetes but suggests a possible disease-duration dependent effect in this relationship as there is an increased prevalence of PD in those with long-duration diabetes after adjustment for confounding factors. Diabetes duration appears to reflect the effect of the cumulative toxicity of the underlying shared pathological mechanisms between these two diseases. Future studies should further explore this possibility and the effect of good diabetes control in the association between PD and diabetes. 


\section{ACKNOWLEDGEMENTS}

The authors would like to thank the collaborators, contributors and advisers who participated in NEDICES study. Full names and further details can be found on the website http://www.ciberned.es/estudio-nedices

CONFLICT OF INTEREST AND SOURCES OF FUNDING STATEMENT

NEDICES study was sponsored by Spanish Health Research Agency and Spanish

Office of Science and Technology. Information about detailed funding of the

NEDICES study can be found on the Web http://www.ciberned.es/estudio-nedices

No conflicts of interest are reported. 


\section{REFERENCES}

1. Aviles-Olmos I, Limousin P, Lees A, Foltynie T. Parkinson's disease, insulin resistance and novel agents of neuroprotection. Brain. 2013;136(Pt 2):374-384.

2. De Pablo-Fernandez E, Breen DP, Bouloux PM, Barker RA, Foltynie T, Warner TT. Neuroendocrine abnormalities in Parkinson's disease. J Neurol Neurosurg Psychiatry. 2017;88(2):176-185.

3. Athauda D, Foltynie T. Insulin resistance and Parkinson's disease: A new target for disease modification? Prog Neurobiol. 2016.

4. Morales JM, Bermejo FP, Benito-Leon J, et al. Methods and demographic findings of the baseline survey of the NEDICES cohort: a door-to-door survey of neurological disorders in three communities from Central Spain. Public Health. 2004;118(6):426-433.

5. Benito-Leon J, Bermejo-Pareja F, Rodriguez J, Molina JA, Gabriel R, Morales JM. Prevalence of PD and other types of parkinsonism in three elderly populations of central Spain. Mov Disord. 2003;18(3):267-274 .

6. Benito-Leon J, Bermejo-Pareja F, Morales-Gonzalez JM, et al. Incidence of Parkinson disease and parkinsonism in three elderly populations of central Spain. Neurology. 2004;62(5):734-741.

7. Driver JA, Smith A, Buring JE, Gaziano JM, Kurth T, Logroscino G.

Prospective cohort study of type 2 diabetes and the risk of Parkinson's disease. Diabetes Care. 2008;31(10):2003-2005.

8. $\mathrm{Xu} Q$, Park $Y$, Huang $X$, et al. Diabetes and risk of Parkinson's disease. Diabetes Care. 2011;34(4):910-915. 
9. Noyce AJ, Bestwick JP, Silveira-Moriyama L, et al. Meta-analysis of early nonmotor features and risk factors for Parkinson disease. Ann Neurol. 2012;72(6):893-901 .

10. Lu L, Fu DL, Li HQ, Liu AJ, Li JH, Zheng GQ. Diabetes and risk of Parkinson's disease: an updated meta-analysis of case-control studies. PLoS One. 2014;9(1):e85781.

11. Cereda E, Barichella M, Pedrolli C, et al. Diabetes and risk of Parkinson's disease. Mov Disord. 2013;28(2):257.

12. Cereda E, Barichella M, Pedrolli C, et al. Diabetes and risk of Parkinson's disease: a systematic review and meta-analysis. Diabetes Care. 2011;34(12):26142623.

13. Cereda E, Barichella M, Cassani E, Caccialanza R, Pezzoli G. Clinical features of Parkinson disease when onset of diabetes came first: A case-control study. Neurology. 2012;78(19):1507-1511.

14. Giuntini M, Baldacci F, Del Prete E, Bonuccelli U, Ceravolo R. Diabetes is associated with postural and cognitive domains in Parkinson's disease. Results from a single-center study. Parkinsonism Relat Disord. 2014;20(6):671-672.

15. Aviles-OImos I, Dickson J, Kefalopoulou Z, et al. Exenatide and the treatment of patients with Parkinson's disease. J Clin Invest. 2013;123(6):2730-2736. 


\section{TABLES}

Table 1. Diagnostic criteria for parkinsonism and etiologic subgroups. ${ }^{5,6}$

\begin{tabular}{|l|l|}
\hline Diagnosis & Criteria \\
\hline Parkinsonism & $\begin{array}{l}\text { Presence of } \geq 2 \text { cardinal signs (tremor, bradykinesia, rigidity, } \\
\text { postural disturbances) in a subject not on antiparkinsonian } \\
\text { medication or } \\
\text { Presence of } \geq 1 \text { cardinal sign in a patient on antiparkinsonian } \\
\text { medication }\end{array}$ \\
\hline $\begin{array}{l}\text { Drug-induced } \\
\text { parkinsonism }\end{array}$ & $\begin{array}{l}\text { Treatment with dopaminergic blocking drugs within } 6 \text { months } \\
\text { before symptom onset and } \\
\text { Previous negative history of parkinsonian symptoms or signs and } \\
\text { Improvement or resolution of the symptoms within } 6 \text { months after } \\
\text { discontinuation of the offending drug a }\end{array}$ \\
\hline $\begin{array}{l}\text { Vascular } \\
\text { parkinsonism }\end{array}$ & $\begin{array}{l}\text { Presence of } \geq 2 \text { of the following features: } \\
\text { History of cerebrovascular disease with sudden onset and } \\
\text { stepwise progression of parkinsonian symptoms or } \\
\text { Arterial hypertension or } \\
\text { Emotional incontinence and pseudobulbar palsy or } \\
\text { Broad-based rigid gait or } \\
\text { Widespread pyramidal signs }\end{array}$ \\
\hline $\begin{array}{l}\text { Atypical } \\
\text { parkinsonism }\end{array}$ & $\begin{array}{l}\text { Parkinson-plus syndromes, parkinsonism secondary to central } \\
\text { nervous system infection, repeated head trauma, brain tumors or } \\
\text { other conditions affecting the basal ganglia b }\end{array}$ \\
\hline $\begin{array}{l}\text { Idiopathic } \\
\text { Parkinson's } \\
\text { disease }\end{array}$ & $\begin{array}{l}\text { Presence of parkinsonism and enough clinical information to } \\
\text { exclude vascular, drugs or atypical causes }\end{array}$ \\
\hline $\begin{array}{l}\text { Unspecified } \\
\text { parkinsonism }\end{array}$ & $\begin{array}{l}\text { Presence of parkinsonism with insufficient clinical information to } \\
\text { reach an etiological diagnosis }\end{array}$ \\
\hline
\end{tabular}

Footnotes. ${ }^{a}$ whenever possible; ${ }^{b}$ defined by routine clinical diagnosis. 
Table 2. Demographic and clinical characteristics of participants.

\begin{tabular}{|l|l|l|l|l|}
\hline & $\begin{array}{l}\text { Total } \\
(\mathrm{n}=4998)\end{array}$ & $\begin{array}{l}\text { Parkinson's } \\
\text { disease } \\
(\mathrm{n}=79)\end{array}$ & $\begin{array}{l}\text { Controls } \\
(\mathrm{n}=4919)\end{array}$ & P Value \\
\hline Sex, female (\%) & 57.7 & 45.6 & 57.8 & 0.03 \\
\hline Age, years (IQR $\left.{ }^{\mathrm{a}}\right)$ & $73(68-79)$ & $77(72-82)$ & $73(68-79)$ & $<0.001$ \\
\hline Diabetes (\%) & 16.8 & 17.7 & 16.8 & 0.83 \\
\hline Anti-diabetes therapy & & & & 0.62 \\
\hline None (\%) & 47.5 & 57.1 & 47.3 & \\
\hline Oral (\%) & 36.6 & 35.7 & 36.6 & \\
\hline Insuline (\%) & 15.9 & 7.1 & 16.1 & \\
\hline Diabetes duration, years (IQR) & $5(2-13)$ & $8.5(2-17)$ & $5(2-13)$ & 0.52 \\
\hline$<10$ years (\%) & 65.0 & 50.0 & 65.3 & \\
\hline$\geq 10$ years (\%) & 35.0 & 50.0 & 34.7 & \\
\hline Hypertension (\%) & 50.9 & 59.5 & 50.8 & 0.13 \\
\hline Dyslipemia (\%) & 29.1 & 23.7 & 29.2 & 0.30 \\
\hline Alcohol consumption & & & & 0.24 \\
\hline Never (\%) & 46.2 & 55.9 & 46.0 & \\
\hline Former (\%) & 20.9 & 19.1 & 21.0 & \\
\hline Current (\%) & 32.9 & 25.0 & 33.1 & \\
\hline Smoking & & & & 0.31 \\
\hline Never (\%) & 61.3 & 64.7 & 61.2 & \\
\hline Former (\%) & 26.9 & 29.4 & 26.9 & \\
\hline Current (\%) & 11.8 & 5.9 & 11.9 & \\
\hline Body mass index & & & & 0.13 \\
\hline Underweight (\%) & 1.6 & 5.0 & 1.5 & \\
\hline Normal (\%) & 31.2 & 35.0 & 31.1 & \\
\hline Overweight (\%) & 42.6 & 41.7 & 42.6 & \\
\hline Obese (\%) & 24.6 & 18.3 & 24.7 & \\
\hline Stroke/TIA (\%) & 4.9 & 6.3 & 4.9 & 0.55 \\
\hline DRB drugs (\%) & 4.9 & 4.9 & 6.3 & 0.56 \\
\hline
\end{tabular}

Footnotes. *Only 657 diabetic patients included in the analysis; ainter quartile range; bdopamine receptor blocking drugs. 
Table 3. Association between diabetes and Parkinson's disease (OR and 95\% Cl) according to diabetes status and duration.

\begin{tabular}{|l|l|l|l|l|}
\hline & PD $(\mathrm{n}=79)$ & $\begin{array}{l}\text { Controls } \\
(\mathrm{n}=4919)\end{array}$ & $\begin{array}{l}\text { Unadjusted } \\
\text { model }\end{array}$ & Adjusted model \\
\hline \multicolumn{5}{|l|}{} \\
\hline Diabetes \\
\hline No & $65(1.56 \%)$ & $4091(98.44 \%)$ & 1.0 & 1.0 \\
\hline Yes & $14(1.66 \%)$ & $828(98.34 \%)$ & $1.06(0.60-1.89)$ & $1.89(0.90-3.98)$ \\
\hline Diabetes duration \\
\hline None & $65(1.56 \%)$ & $4091(98.44 \%)$ & 1.0 & 1.0 \\
\hline$<10 y$ & $7(1.64 \%)$ & $420^{*}(98.36 \%)$ & $1.05(0.49-2.26)$ & $1.68(0.70-4.03)$ \\
\hline$\geq 10 y$ & $7(3.04 \%)$ & $223^{*}(96.96 \%)$ & $1.98(0.91-4.28)$ & $3.27(1.21-8.85)$ \\
\hline
\end{tabular}

Footnotes: data shown are $\mathrm{n}(\%)$ or OR $(95 \% \mathrm{Cl})$. Adjusted model: adjusted for sex, age, hypertension, dyslipemia, antidiabetic treatment, alcohol consumption, smoking status, body mass index, presence of cerebrovascular disease and treatment with potential parkinsonism-inducing drugs in the logistic regression analysis. * only 643 controls (from a total of 828) had diabetes duration information available and were included in this analysis. 


\section{FIGURES}

Fig 1. Flow-chart of the study. 